\title{
Using Video to Give More Effective and Engaging Science Talks
}

\author{
Eric B. Brennan* \\ Crop Improvement and Protection Unit, United States Department of Agriculture, Agricultural Research Service, Salinas, CA, \\ United States
}

Science presentations at conferences are an important way that scientists share exciting research discoveries. Some presentations are informative and engaging, but unfortunately many are not. This article describes a novel method (Video Let's Talk, VLT) for more engaging and effective science presentations, where the presenter 1 . makes a video that fills half of the presentation time, 2. shows the video in lieu of a live presentation, and 3. spends the remaining time engaging with the audience. The benefits and challenges of the VLT method are described along with tips on how to do the VLT well. These insights are based on the author's experience giving numerous VLT presentations to scientists, farmers and other groups over the past seven years. The VLT method is timely considering how the COVID pandemic has forced scientists to learn new skills in do it yourself (DIY) video making in order to participate in virtual conferences.

\section{OPEN ACCESS}

Edited by: Joachim Allgaier, Fulda University of Applied Sciences,

Germany

Reviewed by: Voltaire Alvarado Peterson, University of Concepcion, Chile Dhaval Parmar, Northeastern University, United States

*Correspondence:

Eric B. Brennan eric.brennan@usda.gov

Specialty section: This article was submitted to Science and Environmental Communication, a section of the journal Frontiers in Communication

Received: 15 June 2021 Accepted: 07 September 2021 Published: 28 September 2021

Citation:

Brennan EB (2021) Using Video to Give More Effective and Engaging Science Talks.

Front. Commun. 6:725811. doi: $10.3389 /$ fcomm.2021.725811
Keywords: science communication, conference presentations, oral presentation skills, public understanding of science (PUS), video making, audience engagement, outreach and education

\section{INTRODUCTION}

When I go camping with my family, I often joke that our oatmeal smells like bacon. It's not because we're cooking bacon, but because the odor of sizzling bacon drifts over from nearby campsites as we're eating our delicious oatmeal for breakfast. I've never been a big fan of bacon, but many people are, which is why the bacon, lettuce and tomato (BLT) sandwich is one of the most popular sandwiches in the United States. And that brings me to the focus of this perspective article ... the "VLT" that stands for Video Let's Talk or Video-Let-us-Talk (Figure 1A). It's a novel method of science presentation that I've developed and experimented with for several years, long before the COVID-19 pandemic forced many science meetings to go virtual, and skills like DIY video making to become more important.

I did my first VLT presentation at the Tri-Societies annual meeting (Brennan, 2014). It worked so well that I've used this method for all my presentations at subsequent scientific meetings (Brennan and Cavigelli, 2014; Brennan, 2015; Brennan, 2016; Cavigelli et al., 2016; Brennan, 2017a; Brennan, 2017b; Brennan, 2018a; Brennan, 2018b; Brennan, 2018c; Brennan, 2019b; Brennan, 2019c; Brennan, 2019d; Brennan, 2019e; Brennan, 2019f) (Supplementary Table S1). Furthermore I co-organized a symposium that required this format (Tri-Societies, 2016); based on feedback and my observations, it was one of the most engaging symposiums that year.

For decades, frustrated and concerned scientists have written about the poor quality of presentations at science conferences (Janzen, 1980; Pickett et al., 1991; Brigham, 2010; Wheelwright, 2014; Langin, 2017). One of my favorites begins with: "I am sitting in the 11th incredibly boring 30 min "paper" in 2 days, nodding my head in somnambulistic time, drowsily wondering how we are going to break this cycle"(Janzen, 1980). And a more recent one starts with: "Attending talks at professional meetings is like playing a slot machine: sometimes you win big, but 


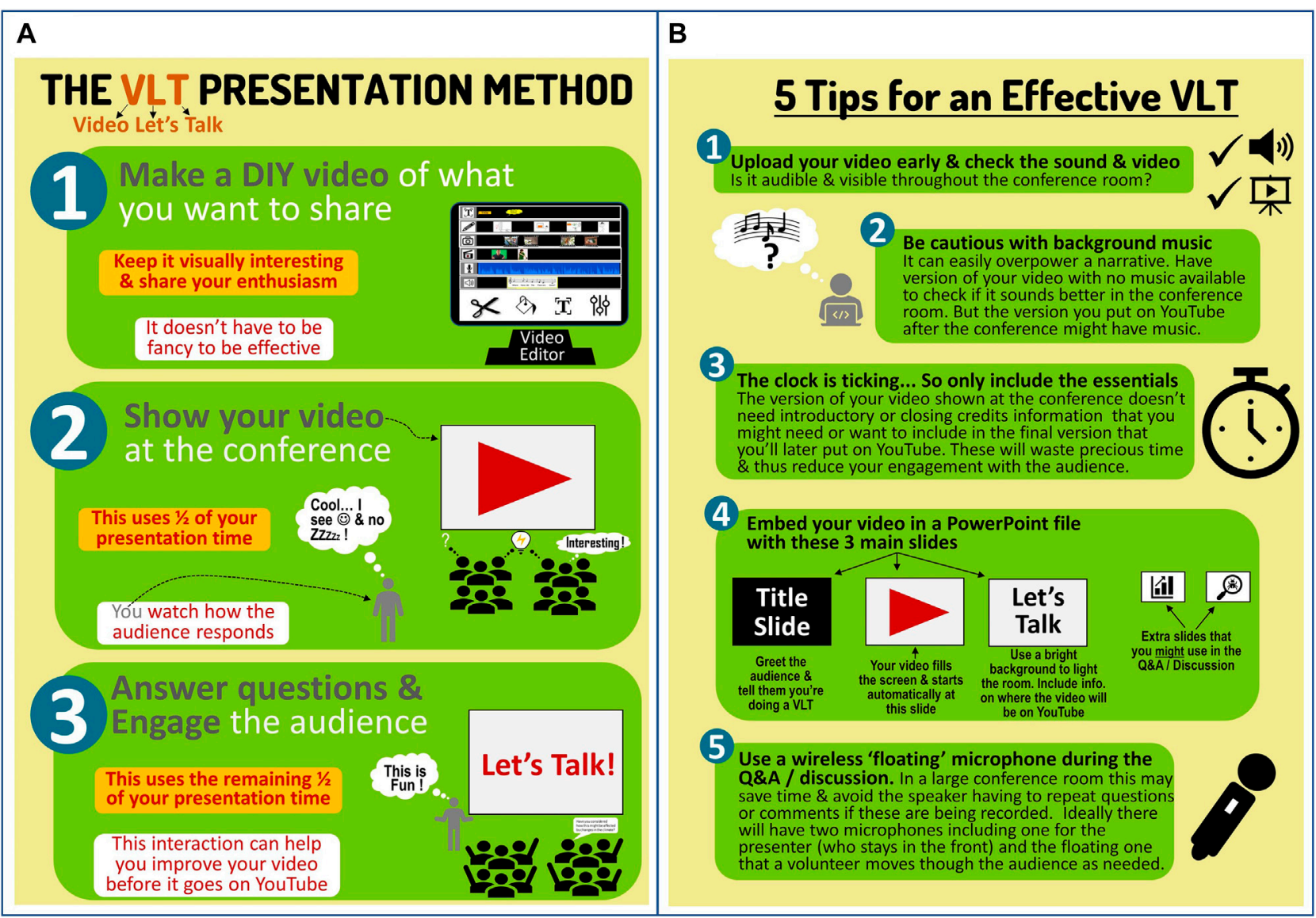

FIGURE 1 | Overview for the Video Let's Talk method (A) and tips on how to do it well (B).

too often the result is disappointment" (Langin, 2017). In the 37 years between these examples, the visual presentation tools that scientists use have changed radically-from $35 \mathrm{~mm}$ slides and overhead projectors to electronic slides in PowerPoint-but what I fear has not changed is the ability of too many science presentations to bore or put their audience to sleep. I've seen this frequently, and as an audience member I unfortunately often find myself more amused by the nodding heads in front of me than by the gory details of the "death by PowerPoint" format that often contributes to this. I believe that the VLT method might help to end this pandemic, and if it succeeds, perhaps VLT could also stand for Vaccine for Lamentable Talks.

\section{BENEFITS OF THE VLT METHOD}

\section{Watching Yourself Present}

This can be painful, but it can help us to see where and how to improve. It forces us to ask important questions (e.g., Am I rushing or speaking in a monotone voice? Are my visuals clear and do they augment my narrative?) Self-reflection by the presenter is a primary benefit of DIY videos that are used in the flipped classroom method of teaching (McCammon, 2014).

\section{Shorter Presentations}

This gives the audience less time to nod off and an incentive to stay focused. This forces us to refine our message, get to the point, and use interesting visuals that minimize the chance of setting off the "Blah-Blahmeter" (a figurative filter that detects the amount of "blah-blah-blah", or unhelpful noise in a presentation (Roam, 2011). You might be thinking that the VLT sounds like the $5 \mathrm{~min}$ "rapid-fire", "lightning" or "ignite talk" formats that have been introduced at many conferences (Lortie, 2017; Berkun, 2019). While similar in some regards, I think the VLT method is far better because you can use visuals more effectively and aren't under pressure to do this live.

\section{Increased Engagement and Interaction}

The VLT method leaves far more time for meaningful dialogue with the audience than typically occurs in live presentations. Audiences appreciate this because it shows that you respect their time and are interested in their input and ideas. During a typical $15 \mathrm{~min}$ presentation slot, the presenter often takes $14 \mathrm{~min}$ for 
their information and leaves only $1 \mathrm{~min}$ for Q\&A. But, interaction is what draws many scientists to conferences, so why not augment that in your presentations. The VLT format may help scientists transition towards two-way science communication (Davies, 2008) that hopefully will spill over into how we communicate with the general public. I've found the VLT method to be effective with science conference audiences, farmers groups, university classes, and the general public.

\section{Accessible Outreach Product}

Your DIY video can be shared on YouTube to increase the impact and reach of your research (Brennan, 2019e; Brennan, 2021). For example, my first VLT presentation (Brennan, 2014) was seen by about 100 conference attendees but since then on YouTube it has gotten more than 19,500 views (an average of 250 monthly). This makes the time investment to make the video worthwhile. Granted, not all those voluntary YouTube viewers may have been paying attention, but the fact that chairs in the back and aisles of science conference rooms fill up first indicates that many people are planning their escape and may not be attentive either. Knowing that you will put the video from your VLT presentation on YouTube will also hopefully motivate you to improve your science communications skills because you know that everybody from your family (kids, grandmother), friends, neighbors, boss (current and future), university students, and colleagues can see you. I always carefully edit the closed captions of my video so that my information is accessible to people who are deaf or hard of hearing. These closed captions can also be translated into multiple languages.

\section{Learning DIY Video Making Skills}

In the past 10 years, a small but growing number of scientists have described the value of learning to make videos to share their research with the world via YouTube (McKee, 2013; Smith, 2018, 2020; Brennan, 2021; Maynard, 2021). Video making skills will have many spillover benefits for those who teach or want to use video to augment information in a paper. For example, my only award winning paper (Brennan, 2018d) was one where I made a "how to" video (Brennan, 2019a) that demonstrated aspects of my paper. DIY video making skills will also be useful if you submit a video for publication in a peer-reviewed video journal like the Journal of Visual Experiments (JOVE). While some scientists might think that professionally made science videos are better, a recent study showed that they receive fewer views on YouTube than videos made by user groups (Welbourne and Grant, 2016). I believe that part of the reason for this discrepancy is because scientists are more likely to feel self-conscious and thus come across as "cold", nervous, and unnatural when they are filmed by a professional crew who they don't know well and that is under time pressure to finish the video shoot.

\section{Better Moderation}

The VLT presentation method makes it much easier for session moderators (i.e., timekeepers) to stay on time. This serious problem still persists though it was thoughtfully lamented with humor and candor decades ago (Cairns, 1989). The author interestingly suggested that to stop speakers from running over "maybe meetings should be replaced by videotapes of speakers".

\section{Helpful Feedback}

Observing an audience watch and react to your video provides valuable feedback to help improve your science communication. For example, Is the audience attentive? Are they laughing when they should be? Do they ask questions that indicate they understood your message? This feedback can help the scientist modify their video before it is posted to YouTube.

\section{CHALLENGES WITH THE VLT METHOD}

\section{Learning to Make DIY Videos}

This takes time but is easier than you might realize. One of the easiest and most visually interesting methods for a DIY science video is the "Hey-Roll, P-Roll" method (Brennan, 2020a; Brennan, 2020b), where one easily cuts between being an onscreen talking head, and showing other visuals. I describe other more complicated methods that I've used in this video (Brennan, 2019d). In any case, the scientist making the video should try to sound enthusiastic and natural even if a script is used. And perhaps most importantly, give yourself the chance to improve over time, and as McKee (2013) explains “don't let perfectionism hold you back."

\section{Less Time to Present Information}

Many scientists may be concerned that the VLT method will not provide them with adequate time to present their research. This concern makes sense particularly if the scientists is new to video making and has not seen the method used effectively. However, although it may seem counterintuitive, I've found that more visual information can be presented in more engaging ways in a short video than can occur during a longer live presentation. This is because the scientist video maker can remove unnecessary pauses, carefully time the appearance of visuals, and redo sections of the presentation that were unclear. And moreover, this can happen in a relaxed setting long before the video is shown.

\section{Audio/Video Setup}

The conference room where the VLT presentation occurs needs adequate speakers so that the video's narrative is clearly audible throughout the room. I always check this beforehand (Figure 1B). If the computer that plays the video is not connected to the room's speakers, one can place the microphone for the presenter near the computer's build in speaker to amplify the audio throughout the room.

\section{Engagement Anxiety}

Allocating half of the presentation time for discussion or questions and answers (Q\&A) may concern some presenters for several reasons (e.g., What if the audience doesn't ask any questions or want to interact? What if one audience member monopolizes the Q\&A? What if they ask questions that I can't answer?). I've always found that audiences are eager to interact and ask questions after the 
video. But, I'm always prepared to expand on material in the video if needed. Another effective engagement strategy is to have audience members discuss something in the video with the person next to them. For example, they might ask their neighbor, in $1 \mathrm{~min}$, what surprised them, and then ask a few people to share that with the whole audience.

\section{Unfair Moderators}

If the moderator of the session fails to keep earlier speakers in the session on time, the moderator might be tempted to not allow the VLT speaker to use their originally allotted time. For example, in a $15 \mathrm{~min}$ presentation slot where a $7.5 \mathrm{~min}$ video is shown, the presenter should not be allowed only 1-2 min for Q\&A. To prevent this problem the presenter should notify the moderator in advance that the VLT method will be used and that the presenter expects their fair share of time for the Q\&A.

\section{Skeptical Scientists}

Some scientists in the audience or who present in the same session as the VLT presentation may not like it because it may threaten to make the standard method of science presentation look boring and less interactive. If you encounter this, keep in mind the words of the great physicist Max Planck, "A new scientific truth does not triumph by convincing its opponents and making them see the light, but rather because its opponents eventually die, and a new generation grows up that is familiar with it." Recent research in the life sciences (Azoulay et al., 2019) has unfortunately found evidence that Planck was correct.

\section{CAVEATS AND RESEARCH NEEDS}

It is important to highlight that my perspective on the VLT method is based on my personal experience with it over the past 7 years and my observations of how well I believe this method worked at a symposium (Tri-Societies, 2016) I co-organized. I am not arguing that this method should be used for all science presentations, or would be most appropriate for all audiences, however, my hope is that this article will encourage other scientists and conference organizers to consider using it. If this occurs, it would be useful for science communication researchers to collect data on the

\section{REFERENCES}

Azoulay, P., Fons-Rosen, C., and Zivin, J. S. G. (2019). Does Science Advance One Funeral at a Time? Am. Econ. Rev. 109, 2889-2920. doi:10.1257/ aer.20161574

Baron, N. (2010). Escape from the Ivory tower: A Guide to Making Your Science Matter. Washington, DC: Island Press.

Baron, N. (2016). So You Want to Change the World? Nature 540 (7634), 517-519. doi:10.1038/540517a

Berkun, S. (2019). Why Are Ignite Talks Only Five Minutes Long? Available at: https://igniteseattle.com/2019/10/15/why-are-ignite-talks-only-five-minuteslong/ (Accessed October 20, 2020).

Bragg, L. (1966). The Art of Talking about Science. Science 154, 1613-1616. doi:10.1126/science.154.3757.1613 effectiveness of the VLT method compared with relatively new methods (i.e., "rapid-fire", "lightning" or "ignite talk") and the more standard science presentation methods.

\section{CONCLUSION}

Communicating science effectively is difficult yet more critical for the survival of our species than ever before. There are many excellent resources to help scientist improve their communication skills (Bragg, 1966; Janzen, 1980; Godin, 2007; Reynolds, 2008; Baron, 2010; Brigham, 2010; Roam, 2011; Ruetz, 2012; McKee, 2013; Wheelwright, 2014; Baron, 2016; Langin, 2017; Olson, 2018; Finkler and Leon, 2019), but we still have a long way to go to incorporate these effectively into our talks. The VLT method has radically improved how I communicate my science and engage my audiences regardless of whether they are scientists, students, farmers, other agricultural professionals, or the public. I hope you'll try this fun and effective method. It won't make your presentations as popular as the BLT sandwich, but it can help move your science communication in that direction.

\section{DATA AVAILABILITY STATEMENT}

The original contributions presented in the study are included in the article/Supplementary Material, further inquiries can be directed to the corresponding author.

\section{AUTHOR CONTRIBUTIONS}

The author confirms being the sole contributor of this work and has approved it for publication.

\section{SUPPLEMENTARY MATERIAL}

The Supplementary Material for this article can be found online at: https://www.frontiersin.org/articles/10.3389/fcomm.2021.725811/ full\#supplementary-material

Brennan, E. B. (2014). Are Legume-Cereal Mixtures a Good Fit for Organic Vegetable Production? : YouTube. Available at: https://www.youtube.com/ watch?v=WREmHa-jFbc (Accessed October 21, 2020).

Brennan, E. B. (2015). A Biological Control Buffet in the Salad Bowl of America. YouTube. Available at: https://www.youtube.com/watch?v=zLvJLHERYJI (Accessed October 21, 2020).

Brennan, E. B. (2016). Sustainability Problems with 'repackaged' Synthetic Nitrogen in Organic Agriculture. YouTube. Available at: www.youtube.com/ watch?v=3GjbnchPhl8 (Accessed October 21, 2020).

Brennan, E. B. (2017a). Cover Cropping on Vegetable Beds: Novel Equipment and Ideas. YouTube. Available at: https://www.youtube.com/watch? $\mathrm{v}=\mathrm{Qm} 56 \times \mathrm{xBu} 8$-s (Accessed October 21, 2020).

Brennan, E. B. (2017b). Furrow Cover Crops for 'Greener' Strawberries and Other Plastic Mulched Crops. YouTube. Available at: https://www.youtube.com/ watch?v=fesxbH03diY (Accessed October 21, 2020). 
Brennan, E. B. (2018a). Juicing Cover crops Are You Nuts? Maybe but Hear Me Out! YouTube. Available at: https://www.youtube.com/watch?v=H1GfRurgqKI (Accessed October 21, 2020).

Brennan, E. B. (2018b). Lessons from Long-Term Cover Crop Research in the "Salad Bowl of the World" YouTube. Available at: https://www.youtube.com/ watch?v=JurC4pJ7Lb4 (Accessed October 21, 2020).

Brennan, E. B. (2018c). A Quick Trip to the "Salad Bowl of the World". YouTube. Available at: https://www.youtube.com/watch?v=M-8tCXXKqNA (Accessed October 21, 2020).

Brennan, E. B. (2018d). The Slide Hammer Seeder: A Novel Tool for Planting Small Seeds. hortte 28, 764-775. doi:10.21273/horttech04122-18

Brennan, E. B. (2019a). How to Make the Slide Hammer Seeder. YouTube. Available at: https://www.youtube.com/watch?v=olO9zX1ggs8 (Accessed October 21, 2020).

Brennan, E. B. (2019b). Ten Steps to Make DIY Science Videos for YouTube. YouTube. Available at: https://youtu.be/bXC-ctoTgKE (Accessed October 21, 2020).

Brennan, E. B. (2019c). Three Tools to Make Science Videos for YouTube. YouTube. Available at: https://youtu.be/LvJPBgZPHuc (Accessed October 21, 2020).

Brennan, E. B. (2019d). Three Types of DIY Videos that Scientists Can Make. YouTube. Available at: https://youtu.be/KOUrERx0uPk (Accessed October 21, 2020).

Brennan, E. B. (2019e). Why Should Scientists Be on YouTube? Bamboo, Oil \& Ice Cream!. YouTube. Available at: https://youtu.be/Ldf_6gbYJn0 (Accessed October 21, 2020)

Brennan, E. B. (2019f). Using Cover Crops as Undercover Diagnostic Tools for Farmers and Scientists. YouTube. Available at: https://youtu.be/EgxoFx1PMK8 (Accessed October 21, 2020).

Brennan, E. B. (2020a). How to Make Visually-Interesting \& Engaging Educational Video with Camtasia. YouTube. Available at: https://youtu.be/EK71QW4vSzA (Accessed October 21, 2020).

Brennan, E. B. (2020b). A Novel DIY Video Making Method for Busy Teachers, Professors \& Scientists. YouTube. https://youtu.be/2UHfaRF0TEY (Accessed October 21, 2020).

Brennan, E. B. (2021). Why Should Scientists Be on YouTube? It's All about Bamboo, Oil and Ice Cream. Front. Commun. 6 (37), 586297. doi:10.3389/ fcomm.2021.586297

Brennan, E. B., and Cavigelli, M. A. (2014). Organic versus Conventional Comparison - a Devil without details.: YouTube. Available at: https:// www.youtube.com/watch? $\mathrm{v}=\mathrm{os}-\mathrm{aM} 4 \mathrm{FqPUA}$ (Accessed October 21, 2020).

Brigham, R. M. (2010). Talking the Talk: Giving Oral Presentations about Mammals for Colleagues and General Audiences. J. Mammalogy 91 (2), 285-292. doi:10.1644/09-mamm-a-271.1

Cairns, J. (1989). Speaking at Length. Bioscience 39 (9), 632-633. doi:10.2307/ 1311093

Cavigelli, M., Tomeck, M. B., and Brennan, E. B. (2016). What Our Organic Gardens Taught Us about the Challenges of Organic Regulations. YouTube. Available at: https://www.youtube.com/watch? $\mathrm{v}=\mathrm{gOhXMYfgLoI}$ (Accessed October 21, 2020).

Davies, S. R. (2008). Constructing Communication. Sci. Commun. 29 (4), 413-434. doi:10.1177/1075547008316222

Finkler, W., and Leon, B. (2019). The Power of Storytelling and Video: a Visual Rhetoric for Science Communication. Jcom 18, A02. doi:10.22323/2.18050202
Godin, S. (2007). Really Bad Powerpoint. Available at: https://seths.blog/2007/01/ really_bad_powe/ (Accessed July 14, 2020).

Janzen, D. H. (1980). Pleas from a Symposium Goer. Bull. Ecol. Soc. America 61, 170-171. doi:10.1002/bes2.1980.61.issue-3

Langin, K. M. (2017). Tell Me a story! A Plea for More Compelling Conference Presentations. The Condor 119, 321-326. doi:10.1650/CONDOR-16-209.1

Lortie, C. J. (2017). Ten Simple Rules for Short and swift Presentations. Plos Comput. Biol. 13 (3), e1005373. doi:10.1371/journal.pcbi.1005373

Maynard, A. D. (2021). How to Succeed as an Academic on YouTube. Front. Commun. 5 (130). doi:10.3389/fcomm.2020.572181

McCammon, L. (2014). Rethinking the Flipped Classroom Pitch. YouTube. Available at: https://www.youtube.com/watch?v=s0ECkz8z2pU (Accessed July 7, 2020).

McKee, C. L. (2013). The Scientist Videographer. eBook.

Olson, R. (2018). Don't Be Such A Scientist. Washington, DC: Island Press.

Pickett, S. T. A., Hall, B. E., and Pace, M. L. (1991). Strategy and Checklist for Effective Scientific Talks. Bull. Ecol. Soc. America 72, 8-11. doi:10.1002/ bes2.1991.72.issue-2

Reynolds, G. (2008). Presentation Zen: Simple Ideas on Presentation Design and Delivery. Berkeley: New Rider.

Roam, D. (2011). Blah Blah Blah: What to Do when Words Don't Work. New York: Portfolia/Penguin.

Ruetz, C. R. (2012). "Poster and Oral Presentations at Professional Meetings," in Scientific Communication for Natural Resource Professionals. Editor T. E.L. Cecil A. Jennings and Bruce Vondracek (American Fisheries Society), 143-153.

Smith, A. A. (2018). YouTube Your Science. Nature 556 (7701), 397-398. doi:10.1038/d41586-018-04606-2

Smith, A. A. (2020). Broadcasting Ourselves: Opportunities for Researchers to Share Their Work through Online Video. Front. Environ. Sci. 8 (150). doi:10.3389/fenvs.2020.00150

Tri-Societies (2016). Symposium--Sustainability Challenges in Organic Agriculture. Available at: https://scisoc.confex.com/scisoc/2016am/ webprogram/Session15901.html (Accessed October 20, 2020).

Welbourne, D. J., and Grant, W. J. (2016). Science Communication on YouTube: Factors that Affect Channel and Video Popularity. Public Underst Sci. 25 (6), 706-718. doi:10.1177/0963662515572068

Wheelwright, N. T. (2014). Plea from Another Symposium Goer. Front. Ecol. Environ. 12 (2), 98-99. doi:10.1890/14.Wb.002

Conflict of Interest: The author declares that the research was conducted in the absence of any commercial or financial relationships that could be construed as a potential conflict of interest.

Publisher's Note: All claims expressed in this article are solely those of the authors and do not necessarily represent those of their affiliated organizations, or those of the publisher, the editors and the reviewers. Any product that may be evaluated in this article, or claim that may be made by its manufacturer, is not guaranteed or endorsed by the publisher.

Copyright $\odot 2021$ Brennan. This is an open-access article distributed under the terms of the Creative Commons Attribution License (CC BY). The use, distribution or reproduction in other forums is permitted, provided the original author(s) and the copyright owner(s) are credited and that the original publication in this journal is cited, in accordance with accepted academic practice. No use, distribution or reproduction is permitted which does not comply with these terms. 